\section{MARKET YOUR PRACTICE}

Dental care plan provider Munroe Sutton will market your practice in a variety of ways including an online provider search, daily database updates with agents and groups, printed directories, and multi-lingual assistance to help patients find the ideal treatment provider.

Now you no longer have to waste valuable time and capital on marketing your services to the wrong audience. Munroe Sutton enables you to access a large pool of patients and allows them to search for you, ensuring you always have a reassuringly full diary and a vastly improved cash flow absolutely free.

With Munroe Sutton you will fulfil your professional duties, whilst providing patients with the cost-effective oral healthcare they would otherwise not have been able to afford.

Reader response number 54

\section{COLOURFUL CANNULAS}

Dürr Dental's colourful range of universal cannulas are available in both $16 \mathrm{~mm}$ and $11 \mathrm{~mm}$ sizes. Durr cannulas aspirate large amounts of secretions with the minimum of noise, even when operated at high volume flow.

They can also be relied upon to minimise aerosol-cloud, thus protecting you and your assistant. The cannulas are designed with the patient's comfort in mind as well as the ease of use for the operator.

The smooth edges do not have corners which means they avoid pressure sores and are much more comfortable. Autoclavable at $134^{\circ} \mathrm{C}$ they are reliable

\section{SOURCE FLEXIBLE LOANS}

Regulated by the Financial Services Authority, money4dentists is the trusted name providing financial advice and their expert team is qualified to source flexible loans with the most competitive interest rates.

money4dentists provides the most appropriate advice for each individual and backs up all guidance and support by written evidence. With over as well as colourful. Cannulas are now available in turquoise, royal blue, bright pink, yellow or orange as well as the more conventional grey. As well as a choice of colour, you also have a choice of size - either adult or child.

\section{Reader response number 55}

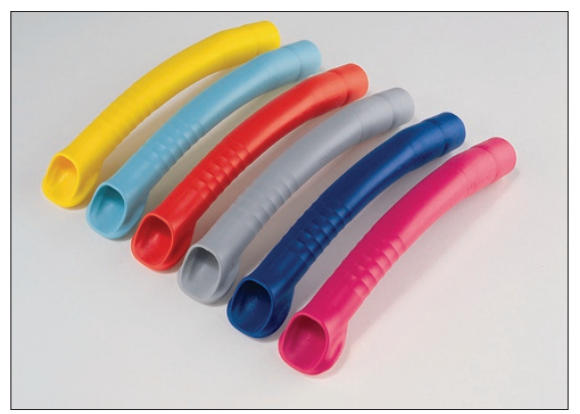

55 years experience, the team has provided easy to understand, independent and impartial advice to UK based dental professionals and delivered the best deals to satisfy their needs.

For any protection, tax, investment or retirement advice, contact expert independent financial planners money4dentists and discuss how to take control of your finances and your future.

Reader response number 56

\section{COMPLETE DISINFECTION WITHOUT RESIDUE}

The Saniswiss biosanitizer automate from Bambach will disinfect your entire surgery overnight at just the press of a button. This surgery atomiser dispenses the Saniswiss biosanitizer directly into your surgery.

Being airborne, the product will get to all of those hard to reach areas efficiently and effectively while its innovative technology converts germs utilising a unique patented super oxygenised water solution.

It in effect 'digests' the virus, bacteria or fungi ensuring complete disinfection without any of the inherent risks associated with alcohol or aldehyde based products and without leaving any residue on the surfaces.

To take full advantage of a deeply cleaned surgery carry out your usual disinfecting routine throughout the day; before you leave in the evening activate the Saniswiss biosanitizer automate.

A fine mist is dispensed automatically, which combines with the oxygen in the air to give a $100 \%$ guarantee of a perfectly disinfected surgery. Bambach are offering a five day free trial complete with a petri dish kit so that you can see the effectiveness for yourself before and after use.

Reader response number 57

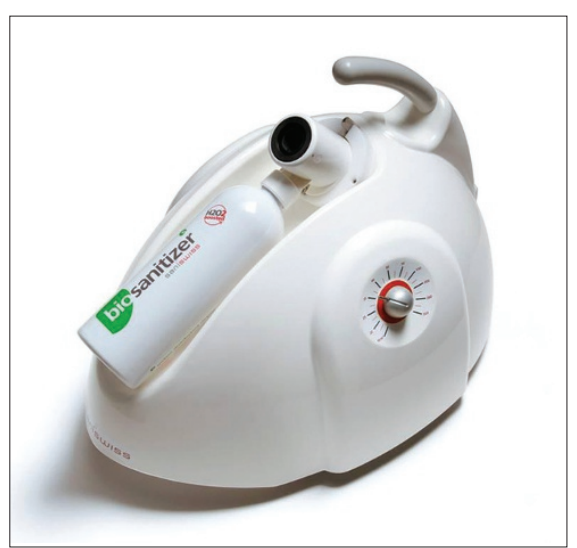

\title{
EXPERT SUPPORT FOR PURCHASING A PRACTICE
}

Essential Money is a firm of independent financial advisers specialising in the dental profession, offering expertise to help navigate through the challenges of purchasing a practice.

Having worked with hundreds of dental practitioners from across the coun- try, Essential Money has the skills and knowledge to help at all stages, including what you need to know to prepare a finance proposal, how to select and negotiate with the right lender, and how to make sure the relevant insurances are in place. It offers advice on pensions, mortgages, retirement planning, savings and investments.

As a team dedicated to dentists, and members of the Association of Specialist Providers to Dentists (ASPD), Essential Money has a detailed understanding of the circumstances specific to the profession.

Reader response number 58 